\title{
Analisis Pengaruh Parameter Operasional dan Penggunaan Stabilizer terhadap Perilaku Arah Belok Mobil Toyota Fortuner 4.0 V6 SR (AT 4X4)
}

\author{
Deva Andriansyah dan I Nyoman Sutantra \\ Jurusan Teknik Mesin, Fakultas Teknologi Industri, Institut Teknologi Sepuluh Nopember (ITS) \\ Jl. Arief Rahman Hakim, Surabaya 60111 Indonesia \\ e-mail: tantra@me.its.ac.id
}

\begin{abstract}
Abstrak-Salah satu tipe mobil yang diminati oleh masyarakat Indonesia yaitu Toyota Fortuner yang termasuk dalam kelas mobil SUV (sport utility vehicle). Dalam pengoperasiannya mobil SUV harus mampu memberikan keamanan dan kenyamanan bagi pengendaranya. Salah satu faktor penunjang dari segi keamanan mobil ini yaitu perilaku arah beloknya. Dengan harga jual yang relatif tinggi di Indonesia, diharapkan mobil ini dapat memberikan perilaku arah belok yang baik. Terdapat dua tahapan dalam peneltian ini yaitu tahap analisis dan uji jalan pada radius belok tetap, 10 meter. Pada tahap analisis dilakukan perhitungan berdasarkan analisa slip, skid, dan guling untuk mengetahui perilaku arah belok mobil dengan variasi pada parameter operasionalnya yaitu: jumlah penumpang, kecepatan, sudut belok, kondisi permukaan jalan, dan tekanan ban. Selain itu, analisis pengaruh penggunaaan stabilizer terhadap perilaku arah belok mobil juga dilakukan. Uji jalan dilakukan untuk mengetahui Koefisien Understeer (Kus) dari mobil tersebut pada jalan aspal dan tanah dengan kondisi mobil tanpa dan menggunakan stabilizer. Hasil yang didapatkan dari uji jalan akan dibandingkan dengan hasil dari analisis perhitungan. Hasil penelitian ini menunjukkan bahwa mobil Toyota Fortuner mengalami kondisi belok paling baik ketika dinaiki oleh 2 orang penumpang dengan tekanan ban sebesar 35 Psi dan melintas pada jalan aspal karena kendaraan lebih sedikit mengalami oversteer dan memiliki (KUS) positif terkecil serta tidak mudah mengalami skid. Penggunaan stabilizer pada mobil Toyota Fortuner tidak berpengaruh terhadap perilaku arah beloknya karena Kus yang dihasilkan pada uji jalan nilainya hampir sama yaitu 1,8045 dan 1,8115 pada jalan aspal serta 2,151 dan 2,1641 pada jalan tanah. Namun, penggunaan stabilizer bermanfaat untuk memperkecil sudut guling ketika mobil berbelok.
\end{abstract}

Kata Kunci-stabilizer, slip, skid, understeer, oversteer.

\section{PENDAHULUAN}

$\mathrm{P}$ ada situs resmi Badan Pusat Statistik Nasional (BPS) pada tahun 2013 silam, tercatat bahwa terdapat sebelas ribu lebih unit mobil di Indonesia [1]. Salah satu mobil yang diminati oleh masyarakat Indonesia ialah Toyota Fortuner yang termasuk jenis mobil SUV (Sport Utility Vehicle). Mobil SUV merupakan jenis mobil penumpang yang menggabungkan konsep mobil Off-Road dan On-Road. Selain mengutamakan kenyamanan dalam berkendara, mobil SUV juga harus mampu memberikan tingkat keamanan yang tinggi. Apabila tingkat kenyamanan dan kemanannya tidak seimbang maka dapat memberikan resiko yang besar bagi pengendaranya. Penelitian dari Dukkipati dkk. [2] menyebutkan bahwa pada periode 1985-1990 mobil SUV menyumbang sebesar 10,75\% dari total kecelakaan mobil yang terjadi di Amerika Serikat dan jumlah itu meningkat pada tahun 2002 yakni sebesar $25,6 \%$. Salah satu faktor yang mempengaruhi tingkat kenyamanan dan keamanan kendaraan yaitu perilaku arah kendaraan saat berbelok. Perilaku arah belok kendaraan itu sendiri erat kaitannya dengan handling performance dan kondisi operasional dari kendaraan tersebut seperti kecepatan, sudut belok, tekanan ban, dan sebagainya. Penelitian dari Uys dkk. [3] menyebutkan bahwa salah satu parameter yang harus diperhatikan untuk meningkatkan handling performance kendaraan yaitu sudut guling yang terjadi ketika kendaraan berbelok. Dengan memperkecil sudut guling tersebut, maka handling performance kendaraan akan meningkat. Penelitian dari P. H. Cronje dan P. S. Els pada tahun 2009 terhadap mobil Land Rover Defender 110 menyebutkan bahwa pada pengaturan soft suspension penggunaan Active Anti Roll Bar (AARB) dapat mengurangi sudut guling maksimum sebesar 74\% daripada tanpa menggunakan Anti Roll Bar (ARB) dan sebesar $45 \%$ pada pengaturan stiff suspension. Sedangkan apabila dibandingkan dengan menggunakan ARB pasif, AARB dapat mengurangi sudut guling maksimum sebesar 55\% pada pengaturan soft suspension dan $40 \%$ pada pengaturan stiff suspension [4].

Tujuan dilakukannya penelitian ini yaitu untuk mengetahui perilaku arah belok mobil Toyota Fortuner dengan memperhitungkan pengaruh dari parameter operasionalnya serta penggunaan stabilizer pada mobil tersebut.

\section{METODOLOGI PENELITIAN}

Penelitian ini dilakukan dengan beberapa tahap yaitu dimulai dengan studi literatur untuk mendapatkan spesifikasi kendaraan. Kemudian mencari kekakuan dari stabilizer yang terpasang pada kendaraan. Dilanjutkan dengan melakukan analiasa perilaku arah belok kendaraan melalui perhitungan berdasarkan metode analisa slip, skid, dan guling. Kemudian yang terakhir yaitu melakukan uji jalan pada kendaraan untuk mendapatkan nilai $\mathrm{K}_{\mathrm{US}}$.

\section{A. Analisa Perhitungan}

\section{A.1. Titik Berat Kendaraan}

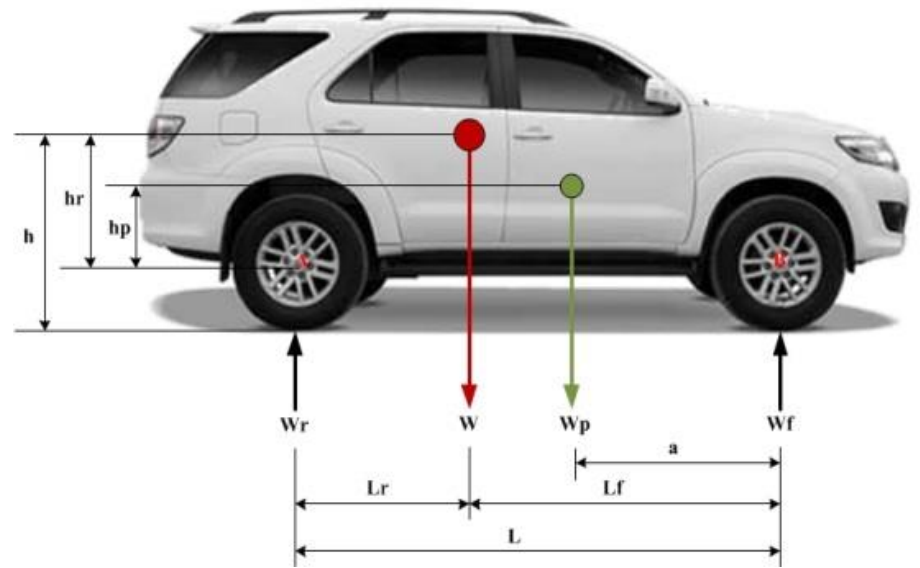

Gambar 1. Free body diagram berat mobil Toyota Fortuner dengan penambahan penumpang. 
Titik berat dari mobil Toyota Fortuner dapat diketahui berdasarkan Free Body Diagram (FBD) pada gambar 1 dan 2.

$\begin{aligned} \mathrm{L}_{\mathrm{f}} & =\frac{\mathrm{W}_{\mathrm{r}} \cdot \mathrm{L}}{\mathrm{W}_{\mathrm{w}}} \\ \mathrm{L}_{\mathrm{f}}{ }^{\prime} & =\frac{\mathrm{w}_{\mathrm{p}} \cdot \mathrm{a}+\mathrm{W}_{\mathrm{L}} \mathrm{L}_{\mathrm{f}}}{\mathrm{W}_{\mathrm{t}}}\end{aligned}$

$\mathrm{L}_{\mathrm{f}}$ adalah letak titik berat awal kendaraan dari sumbu roda depan, L adalah wheelbase kendaraan, $\mathrm{W}$ adalah berat kendaraan, $\mathrm{W}_{\mathrm{r}}$ adalah berat kendaraan bagian belakang, $\mathrm{W}_{\mathrm{p}}$ adalah berat penumpang, dan a adalah jarak titik berat penumpang dari sumbu roda depan, dan $\mathrm{W}_{\mathrm{t}}$ adalah berat total kendaraan setelah penambahan penumpang. Letak titik berat kendaraan setelah penambahan penumpang $\left(\mathrm{L}_{\mathrm{f}}\right.$ ') dapat dicari menggunakan (2). Tinggi titik berat kendaraan kosong dari tanah (h) dan setelah penambahan penumpang (h') dapat dicari menggunakan (4) dan (6) berdasarkan FBD pada gambar 2. Dimana $\mathrm{W}_{\mathrm{f} \theta}$ adalah berat kendaraan bagian depan ketika ditimbang pada posisi miring, $\mathrm{h}_{\mathrm{p}}$ adalah tinggi dari titik berat penumpang, dan $\mathrm{r}$ adalah jari-jari roda kendaraan.

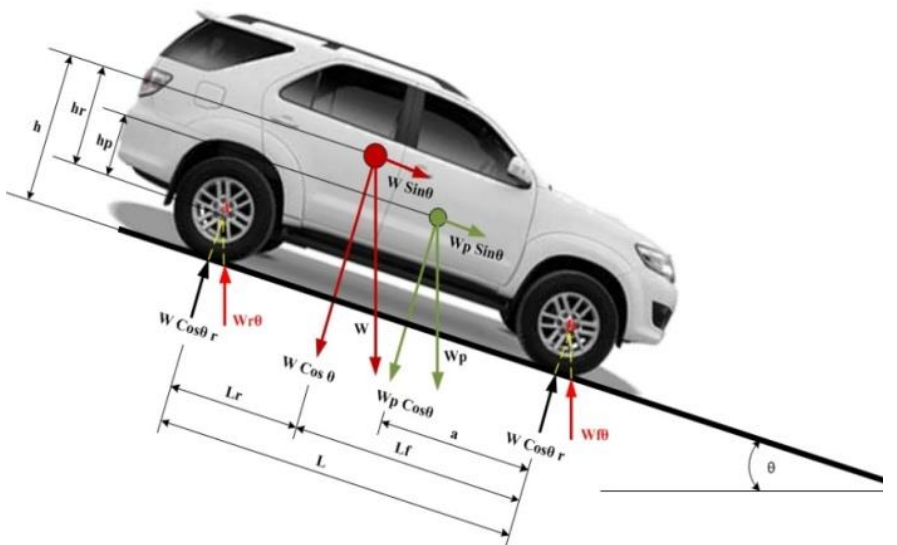

Gambar 2. FBD mobil Toyota Fortuner dengan posisi membentuk sudut $\theta$ setalah penambahan penumpang.

$$
\begin{aligned}
& h_{r}=\frac{w_{f \theta} \cdot L-W L_{r}}{w \tan \theta} \\
& h=h_{r}+r \\
& h_{r}{ }^{\prime}=\frac{W \cdot h_{r}+w_{p} \cdot h_{p}}{w+w_{p}} \\
& h^{\prime}=h_{r}{ }^{\prime}+r
\end{aligned}
$$

\section{A.2. Kekakuan Stabilizer}

Penggunaan stabilizer pada kendaraan dapat membantu mengurangi besarnya sudut guling ketika kendaraan berbelok. Besarnya kekakuan dari stabilizer kendaraan dapat diketahui berdasarkan (7) yang mengacu pada gambar 3.

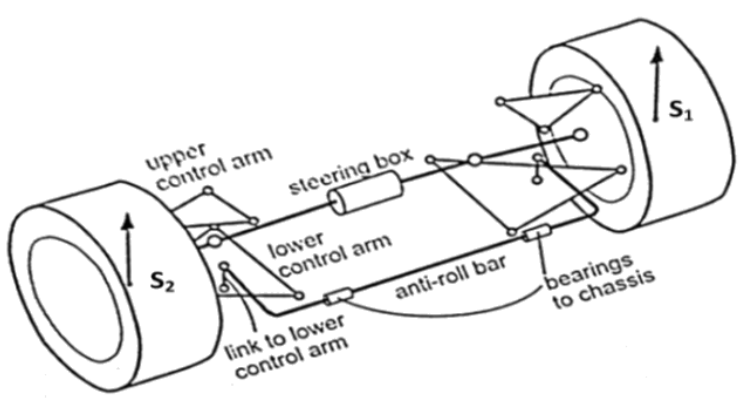

Gambar 3. Sistem suspensi dengan penambahan anti roll bar [5].

$\mathrm{F}_{\mathrm{arb}}= \pm \mathrm{R}_{\mathrm{s}}\left(\mathrm{S}_{1}-\mathrm{S}_{2}\right)$

$F_{\text {carb }}$ merupakan gaya yang diterima oleh stabilizer pada ujung-ujungnya, $S_{1}$ dan $S_{2}$ merupakan perpindahan vertikal pada ban akibat terjadinya body roll, dan $\mathrm{R}_{\mathrm{s}}$ adalah kekakuan stabilizer.

\section{A.3. Gaya yang Bekerja pada Kendaraan Belok}

Gaya-gaya yang terjadi pada setiap ban kendaraan dapat diketahui berdasarkan FBD pada gambar 4 dan 5 .

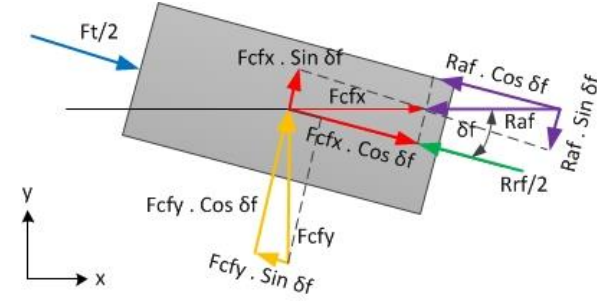

Gambar 4. Gaya-gaya yang terjadi pada roda depan kendaraan.

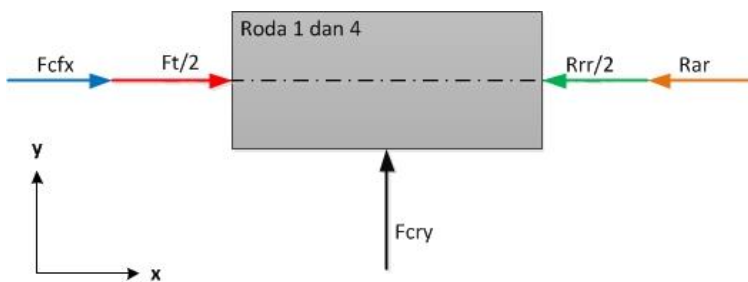

Gambar 5. Gaya-gaya yang terjadi pada roda belakang kendaraan.

Dimana,

$\mathrm{m}$ = Massa kendaraan

$\mathrm{V}=$ Kecepataan kendaraan belok

$\mathrm{R}=$ Radius belok jalan

$F_{c}=$ Gaya sentrifugal yang terjadi pada kendaraan

$\mathrm{F}_{\mathrm{cx}}=$ Gaya sentrifugal ke arah longitudinal

$F_{c y}=$ Gaya sentrifugal ke arah lateral

$\mathrm{F}_{\mathrm{t}}=$ Gaya dorong kendaraan dengan kecepatan konstan

$\mathrm{R}_{\mathrm{a}}=$ Gaya hambat aerodinamika kendaraan

$\mathrm{R}_{\mathrm{r}}=$ Gaya hambat rolling yang terjadi pada ban kendaraan

$\delta \mathrm{f}=$ Sudut belok kendaraan

Gaya Longitudinal $\left(\mathrm{F}_{\mathrm{x}}\right)$ :

$$
\begin{aligned}
& \mathrm{F}_{\mathrm{x} 1}=\frac{1}{2}\left[\frac{\mathrm{F}_{\mathrm{t}}}{2}+\frac{\mathrm{L}_{\mathrm{f}}}{\mathrm{L}}\left(\mathrm{F}_{\mathrm{cx}}-R_{a}\right)-\mathrm{R}_{\mathrm{rr}}\right] \\
& \mathrm{F}_{\mathrm{x} 2}=\frac{1}{2}\left[\frac{\mathrm{F}_{\mathrm{t}}}{2}+\frac{\mathrm{L}_{\mathrm{r}}}{\mathrm{L}}\left(F_{c x}-R_{a}\right) \operatorname{Cos} \delta_{\mathrm{f}}-\frac{\mathrm{L}_{\mathrm{r}}}{\mathrm{L}} \mathrm{F}_{\mathrm{cy}} \cdot \operatorname{Sin} \delta_{\mathrm{f}}-\mathrm{R}_{\mathrm{rf}}\right] \\
& \mathrm{F}_{\mathrm{x} 3}=\frac{1}{2}\left[\frac{\mathrm{F}_{\mathrm{t}}}{2}+\frac{\mathrm{L}_{\mathrm{r}}}{\mathrm{L}}\left(F_{c x}-R_{a}\right) \operatorname{Cos} \delta_{\mathrm{f}}-\frac{\mathrm{L}_{\mathrm{r}}}{\mathrm{L}} \mathrm{F}_{\mathrm{cy}} \cdot \operatorname{Sin} \delta_{\mathrm{f}}-\mathrm{R}_{\mathrm{rf}}\right] \\
& \mathrm{F}_{\mathrm{x} 4}=\frac{1}{2}\left[\frac{\mathrm{F}_{\mathrm{t}}}{2}+\frac{\mathrm{L}_{\mathrm{f}}}{\mathrm{L}}\left(\mathrm{F}_{\mathrm{cx}}-R_{a}\right)-\mathrm{R}_{\mathrm{rr}}\right]
\end{aligned}
$$

\section{Gaya Lateral $\left(\mathrm{F}_{\mathrm{y}}\right)$ :}

$$
\begin{aligned}
& \mathrm{F}_{\mathrm{y} 1}=\frac{\mathrm{F}_{\mathrm{cry}}}{2}=\frac{\mathrm{L}_{\mathrm{f}}}{2 \mathrm{~L}} \mathrm{~F}_{\mathrm{cy}} \\
& \mathrm{F}_{\mathrm{y} 2}=\frac{1}{2}\left[\frac{\mathrm{L}_{\mathrm{r}}}{\mathrm{L}} \mathrm{F}_{\mathrm{cy}} \cdot \operatorname{Cos} \delta_{\mathrm{f}}+\frac{\mathrm{L}_{\mathrm{r}}}{\mathrm{L}}\left(F_{c x}-R_{a}\right) \operatorname{Sin} \delta_{\mathrm{f}}\right] \\
& \mathrm{F}_{\mathrm{y} 3}=\frac{1}{2}\left[\frac{\mathrm{L}_{\mathrm{r}}}{\mathrm{L}} \mathrm{F}_{\mathrm{cy}} \cdot \operatorname{Cos} \delta_{\mathrm{f}}+\frac{\mathrm{L}_{\mathrm{r}}}{\mathrm{L}}\left(F_{c x}-R_{a}\right) \operatorname{Sin} \delta_{\mathrm{f}}\right] \\
& \mathrm{F}_{\mathrm{y} 4}=\frac{\mathrm{F}_{\mathrm{cry}}}{2}=\frac{\mathrm{L}_{\mathrm{f}}}{2 \mathrm{~L}} \mathrm{~F}_{\mathrm{cy}}
\end{aligned}
$$

Gaya Vertikal $\left(\mathrm{F}_{\underline{z}}\right)$ :

$$
\begin{aligned}
& \mathrm{F}_{\mathrm{z} 1}=\frac{\mathrm{L}_{\mathrm{f}}}{2 \mathrm{~L}} \mathrm{~W}-\frac{\mathrm{F}_{\mathrm{cry}} \cdot \mathrm{h}_{\mathrm{gr}}}{\mathrm{t}_{\mathrm{r}}}-\frac{\mathrm{M}_{\mathrm{gr}}}{\mathrm{t}_{\mathrm{r}}}-\frac{\left(\mathrm{F}_{\mathrm{cx}}-\mathrm{R}_{\mathrm{a}}\right) \cdot \mathrm{h}_{\mathrm{gr}}}{2 \mathrm{~L}}-\frac{\mathrm{M}_{\mathrm{p}}}{2 \mathrm{~L}} \\
& \mathrm{~F}_{\mathrm{z} 2}=\frac{\mathrm{L}_{\mathrm{r}}}{2 \mathrm{~L}} \mathrm{~W}-\frac{\mathrm{F}_{\mathrm{cfy}} \cdot \mathrm{h}_{\mathrm{gf}}}{\mathrm{t}_{\mathrm{f}}}-\frac{\mathrm{M}_{\mathrm{gf}}}{\mathrm{t}_{\mathrm{f}}}+\frac{\left(\mathrm{F}_{\mathrm{cx}}-\mathrm{R}_{\mathrm{a}}\right) \cdot \mathrm{h}_{\mathrm{gf}}}{2 \mathrm{~L}}+\frac{\mathrm{M}_{\mathrm{p}}}{2 \mathrm{~L}} \\
& \mathrm{~F}_{\mathrm{z} 3}=\frac{\mathrm{L}_{\mathrm{r}}}{2 \mathrm{~L}} \mathrm{~W}+\frac{\mathrm{F}_{\mathrm{cfy}} \cdot \mathrm{h}_{\mathrm{gf}}}{\mathrm{t}_{\mathrm{f}}}+\frac{\mathrm{M}_{\mathrm{gf}}}{\mathrm{t}_{\mathrm{f}}}+\frac{\left(\mathrm{F}_{\mathrm{cx}}-\mathrm{R}_{\mathrm{a}}\right) \cdot \mathrm{h}_{\mathrm{gf}}}{2 \mathrm{~L}}+\frac{\mathrm{M}_{\mathrm{p}}}{2 \mathrm{~L}} \\
& \mathrm{~F}_{\mathrm{z} 4}=\frac{\mathrm{L}_{\mathrm{f}}}{2 \mathrm{~L}} \mathrm{~W}+\frac{\mathrm{F}_{\mathrm{cry}} \cdot \mathrm{h}_{\mathrm{gr}}}{\mathrm{t}_{\mathrm{r}}}+\frac{\mathrm{M}_{\mathrm{gr}}}{\mathrm{t}_{\mathrm{r}}}-\frac{\left(\mathrm{F}_{\mathrm{cx}}-\mathrm{R}_{\mathrm{a}}\right) \cdot \mathrm{h}_{\mathrm{gr}}}{2 \mathrm{~L}}-\frac{\mathrm{M}_{\mathrm{p}}}{2 \mathrm{~L}}
\end{aligned}
$$


Dimana $\mathrm{M}_{\mathrm{g}}$ adalah momen guling pada kendaraan yang berbelok dan $\mathrm{M}_{\mathrm{p}}$ adalah momen angguk yang terjadi. Besarnya momen guling dan momen angguk dapat diketahui menggunakan persamaan berikut,

$$
\begin{aligned}
& M_{g f}=K_{e q f} \cdot \frac{b_{f}^{2}}{2} \cdot \gamma_{f} \\
& \gamma_{f}=\frac{\frac{L_{r}}{L} \cdot F_{c y} \cdot r_{c}}{K_{e q f} \cdot \frac{b_{f}{ }^{2}}{2}-\frac{L_{r}}{L} \cdot W \cdot r_{c}} \\
& M_{g r}=K_{e q r} \cdot \frac{b_{r}^{2}}{2} \cdot \gamma_{r} \\
& \gamma_{r}=\frac{\frac{L_{f}}{L} \cdot F_{c y} \cdot r_{c}}{K_{e q r} \cdot \frac{b_{r}{ }^{2}}{2}-\frac{L_{f}}{L} \cdot W \cdot r_{c}} \\
& M_{p}=\left(F_{c x}-R_{a}\right) \cdot r_{c}+W \cdot \gamma_{p} \cdot r_{c} \\
& \gamma_{p}=\frac{\left(F_{c x}-R_{a}\right) \cdot r_{c}}{2 K_{e q f} \cdot L_{f}{ }^{2}+2 K_{e q r} \cdot L_{r}{ }^{2}-W \cdot r_{c}}
\end{aligned}
$$

$\mathrm{K}_{\text {eqf }}$ dan $\mathrm{K}_{\text {eqr }}$ merupakan kekakuan ekivalen pegas suspensi-ban-stabilizer depan dan belakang kendaraan. $\mathrm{K}_{\mathrm{sf}}$ dan $\mathrm{K}_{\text {sr }}$ adalah kekakuan pegas suspensi depan dan belakang. $\mathrm{K}_{\text {teqf }}$ dan $\mathrm{K}_{\text {teqr }}$ adalah kekakuan ban depan dan belakang.

Untuk kendaraan tanpa stabilizer,

$$
\begin{aligned}
& \text { - } \mathrm{K}_{\text {eqf }}=\frac{\mathrm{K}_{\mathrm{sf}} \cdot \mathrm{K}_{\text {teqf }}}{\mathrm{K}_{\mathrm{sf}}+\mathrm{K}_{\text {teqf }}} \\
& \text { - } \quad \mathrm{K}_{\text {eqr }}=\frac{\mathrm{K}_{\mathrm{sr}} \cdot \mathrm{K}_{\text {teqr }}}{\mathrm{K}_{\mathrm{sr}}+\mathrm{K}_{\text {teqr }}}
\end{aligned}
$$

Untuk kendaraan yang menggunakan stabilizer,

$$
\text { - } \mathrm{K}_{\text {eqf }}=\frac{\left(\mathrm{K}_{\mathrm{sf}}+\mathrm{Rsf}\right) . \mathrm{K}_{\text {teqf }}}{\left(\mathrm{K}_{\mathrm{sf}}+\mathrm{Rsf}\right)+\mathrm{K}_{\text {teqf }}}
$$

- $\mathrm{K}_{\mathrm{eqr}}=\frac{\left(\mathrm{K}_{\mathrm{sr}}+\mathrm{Rsr}\right) \cdot \mathrm{K}_{\mathrm{teqr}}}{\left(\mathrm{K}_{\mathrm{sr}}+\mathrm{Rsr}\right)+\mathrm{K}_{\mathrm{teqr}}}$

$\Upsilon$ dan $\Upsilon_{\mathrm{p}}$ merupakan sudut guling dan sudut angguk yang terjadi ketika kendaraan berbelok.

\section{A.4. Analisa Slip}

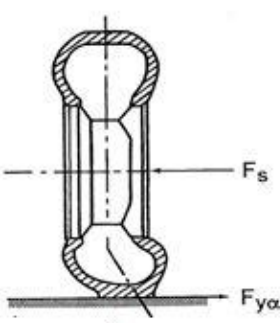

a

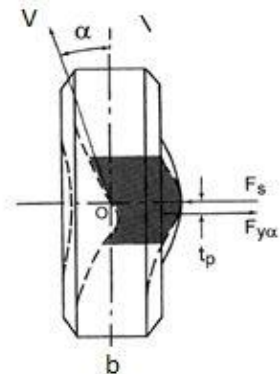

Gambar 6. Mekanisme terjadinya sudut slip pada ban [6]

Gambar 6a menunjukkan adanya gaya ke samping yang menyebabkan terjadinya deformasi pada ban sehingga arah putaran ban mengalami pergeseran sejauh sudut $\alpha$ seperti yang ditunjukkan pada gambar 6b. Sudut itulah yang dinamakan sebagai sudut slip yang terjadi pada ban. Analisa slip digunakan untuk mengetahui besarnya sudut slip yang terjadi pada ban depan dan belakang kendaraan.

$$
\alpha_{1}=\frac{\mathrm{C}_{\mathrm{rp}}}{\mathrm{C}_{\mathrm{rs}}} \cdot \frac{\mathrm{C}_{\mathrm{rx}}}{\mathrm{C}_{\mathrm{ro}}}\left[0,087935\left(\mathrm{~F}_{\mathrm{y} \alpha_{\mathrm{i}}}\right)^{0,79008}-0,005277\left(\mathrm{~F}_{\mathrm{z}_{\mathrm{i}}}\right)\right]
$$

dimana,

$\alpha_{\mathrm{i}} \quad=$ Sudut slip yang terjadi pada setiap roda/ban [ $\left.{ }^{\circ}\right]$ $\mathrm{F}_{\mathrm{y \alpha}_{\mathrm{i}}}=$ Gaya belok (lateral) yang terjadi pada setiap roda/ban [lb]

$\mathrm{F}_{\mathrm{z}_{\mathrm{i}}}$ = Gaya normal yang terjadi pada setiap roda/ban [lb]
$\mathrm{F}_{\mathrm{x}} \quad$ = Gaya longitudinal yang terjadi pada kendaraan [lb]

$\mathrm{C}_{\mathrm{rp}}=3,35+5,30(\mathrm{P})-0,0916(\mathrm{P})^{2}$

$\mathrm{C}_{\mathrm{rs}}=3,35+5,30\left(\mathrm{P}_{\mathrm{s}}\right)-0,0916\left(\mathrm{P}_{\mathrm{s}}\right)^{2}$

$\mathrm{P} \quad=$ Tekanan aktual ban kendaraan [Psi]

$\mathrm{P}_{\mathrm{s}} \quad=$ Tekanan standar ban kendaraan [25 Psi]

$$
\begin{aligned}
\mathrm{C}_{\mathrm{rx}} & =\left[\frac{\mathrm{F}_{\mathrm{y} \alpha \mathrm{i}}+0,107927\left(\mathrm{~F}_{\mathrm{x}}\right)}{161,1398}\right]^{\frac{1}{0,474998}} \\
\mathrm{C}_{\text {ro }} & =\left[\frac{\mathrm{F}_{\mathrm{y} \alpha \mathrm{i}}}{161,1398}\right]^{\overline{0,474998}}
\end{aligned}
$$

Sudut slip dihitung pada setiap ban, dan dirata-rata untuk ban depan $\left(\alpha_{\mathrm{f}}\right)$ dan ban belakang $\left(\alpha_{\mathrm{r}}\right)$. Hasil dari analisa slip ini yaitu membandingkan nilai $\alpha_{\mathrm{f}}$ dan $\alpha_{\mathrm{r}}$. Dimana,

a. $\quad \alpha_{f}>\alpha_{r}$, kendaraan mengalami kondisi understeer

b. $\alpha_{f}=\alpha_{r}$, kendaraan mengalami kondisi netral

c. $\alpha_{f}<\alpha_{r}$, kendaraan mengalami kondisi oversteer

\section{A.5. Analisa Skid}

Gambar 7 menunjukkan ilustrasi mengenai terjadinya fenomena skid yang disebabkan karena besarnya gaya lateral pada ban melebihi gaya gesek yang terajdi antara ban dengan permukaan jalan. Pada Analisa ini akan dihitung batas kecepatan agar kendaraan tidak mengalami skid pada ban depan $\left(\mathrm{V}_{\mathrm{sf}}\right)$ dan belakang $\left(\mathrm{V}_{\mathrm{sr}}\right)$ menggunakan (35) dan (36).

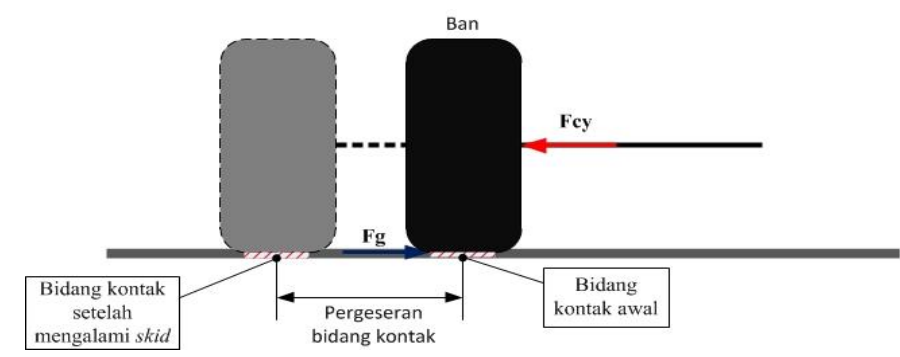

Gambar 7. Ilustrasi ban kendaraan ketika mengalami skid saat berbelok

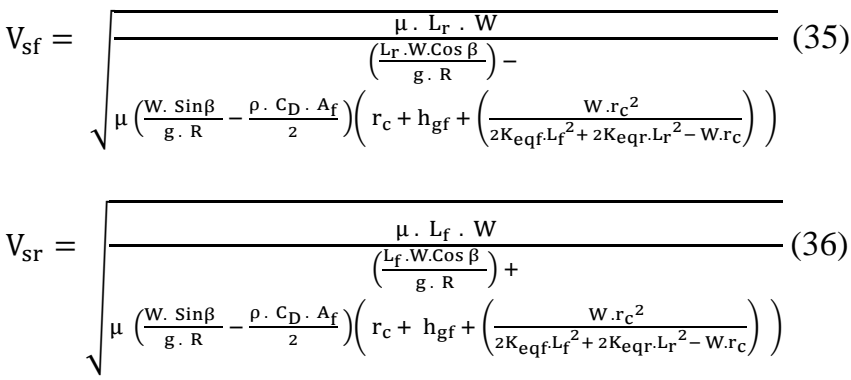

Hasil dari analisa skid ini yaitu:

- Jika $\mathrm{V}_{\mathrm{sf}}<\mathrm{V}_{\mathrm{sr}}$, roda depan akan lebih dahulu mengalami skid sehingga kendaraan akan mengalami understeer.

- Jika $\mathrm{V}_{\text {sf }}>\mathrm{V}_{\text {sr }}$, roda belakang akan lebih dahulu mengalami skid sehingga kendaraan akan mengalami oversteer.

\section{A.6. Analisa Guling}

Pada analisa ini dilakukan perhitungan untuk mengetahui batas kecepatan agar rodakendaraan tidak terangkat ketika berbelok merujuk pada (37) dan (38).

- Jika $\mathrm{V}_{\mathrm{gf}}<\mathrm{V}_{\mathrm{gr}}$, salah satu roda depan akan lebih dahulu terangkat sehingga kendaraan akan mengalami understeer.

- Jika $\mathrm{V}_{\mathrm{gf}}>\mathrm{V}_{\mathrm{gr}}$, salah satu roda belakang akan lebih dahulu terangkat sehingga kendaraan akan mengalami oversteer. 


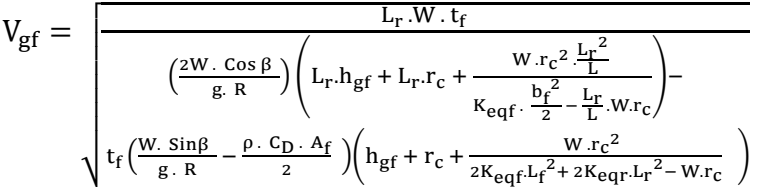

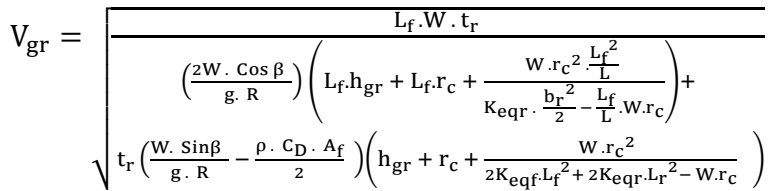

\section{B. Analisa Uji Jalan dengan Radius Belok Tetap}

Langkah-langkah uji jalan yang dilakukan adalah sebagai berikut:

1. Menentukan radius belok $\mathrm{R}$ yang akan dijaga konstan selama pengujian.

2. Membelokkan kendaraan pada kecepatan tertentu $\left(\mathrm{V}_{1}\right)$, dan mempertahankannya sampai membentuk lingkaran dengan radius $R$. Kemudian mencatat sudut beloknya $\left(\delta_{\mathrm{f} 1}\right)$.

3. Menambah kecepatan belok kendaraan sampai kecepatan tertentu $\left(\mathrm{V}_{2}\right)$, dan mempertahankannya sampai membentuk lingkaran dengan radius $\mathrm{R}$. Kemudian mencatat sudut beloknya $\left(\delta_{\mathrm{f} 2}\right)$.

4. Mengulangi langkah 3 sampai kendaraan mengalami skid, ditandai dengan Vehicle Stability Control (VSC) indicator light yang menyala.

5. Mengeplotkan data-data pengujian yang berupa sudut belok $\left(\delta_{\mathrm{f}}\right)$ dan kecepatan belok $(\mathrm{V})$ dalam bidang absis $\left(\frac{\mathrm{V}^{2}}{\mathrm{~g} \cdot \mathrm{R}}\right)$ dan ordinat $\left(\delta_{\mathrm{f}}\right)$ seperti pada gambar 8 .

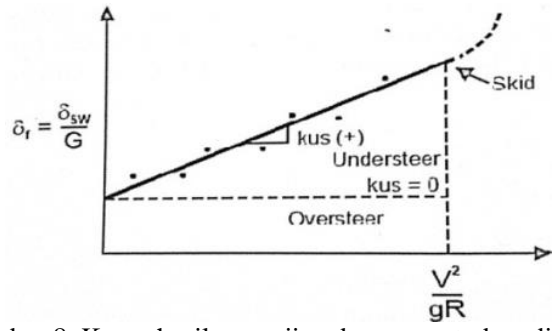

Gambar 8. Kurva hasil pengujian dengan metode radius belok tetap [6].

6. Membuat garis lurus dengan regresi linear terhadap data-data hasil pengujian di atas. Besarnya nilai $\mathrm{K}_{\mathrm{US}}$ merupakan slope dari garis lurus yang dibuat dari data-data di atas.

\section{HASIL DAN PEMBAHASAN}

\section{A. Analisa Perilaku Arah Belok Kendaraan}

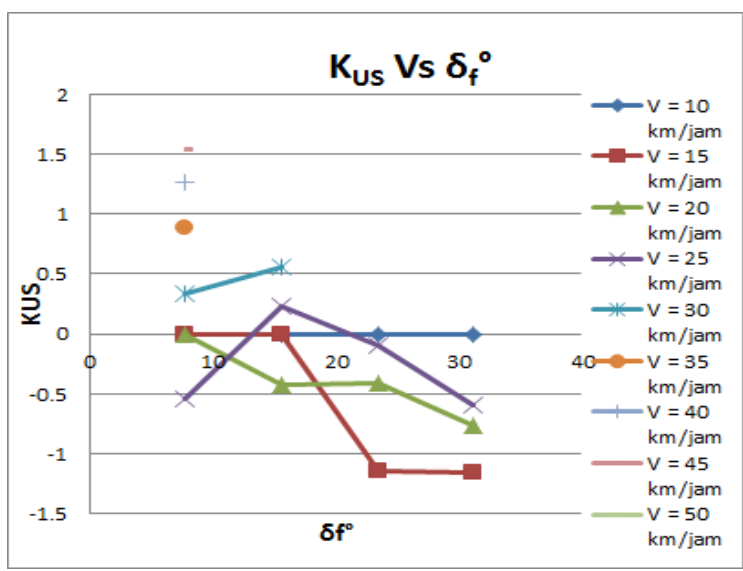

Gambar 9. Grafik nilai $\mathrm{K}_{\mathrm{US}} \mathrm{Vs} \delta \mathrm{f}^{\circ}$ mobil Toyota Fortuner dengan 2 orang penumpang pada jalan aspal.
Gambar 9 merupakan grafik nilai $\mathrm{K}_{\mathrm{US}}$ mobil Toyota Fortuner yang menunjukkan kondisi belok paling baik. Berdasarkan hasil pada gambar 9 dapat diketahui bahwa kendaraan mengalami kondisi oversteer paling sedikit dan memiliki nilai koefisien understeer yang bernilai positif paling kecil dibandingkan ketika dinaiki oleh 4 atau 7 penumpang. Kondisi ini dapat dijumpai ketika kendaraan melintas pada jalan aspal kering.

B. Pengaruh Jumlah Penumpang terhadap Sudut Slip Ban

Tabel 1.

Sudut slip rata-rata ban depan $\left(\alpha_{\mathrm{f}}\right)$ dan belakang $\left(\alpha_{\mathrm{r}}\right)$ kendaraan dengan kecepatan $35 \mathrm{Km} / \mathrm{Jam}$ pada jalan aspal dan tekanan ban 35 Psi.

\begin{tabular}{lcccc}
\hline \hline \multirow{2}{*}{$\delta \mathrm{f}\left[^{\circ}\right]$} & \multicolumn{2}{c}{ 1 Penumpang } & \multicolumn{2}{c}{ 2 Penumpang } \\
& $\alpha \mathrm{f}\left[^{\circ}\right]$ & $\alpha \mathrm{r}\left[{ }^{\circ}\right]$ & $\alpha \mathrm{f}\left[^{\circ}\right]$ & $\alpha \mathrm{r}\left[{ }^{\circ}\right]$ \\
\hline 7,81 & 6,5022 & 6,0749 & 6.6276 & 6.2243 \\
15,62 & SKID & SKID & SKID & SKID \\
23,44 & SKID & SKID & SKID & SKID \\
31,25 & SKID & SKID & SKID & SKID \\
\hline \multirow{2}{*}{$\delta f\left[^{\circ}\right]$} & 4 Penumpang & 7 Penumpang \\
& $\alpha f\left[^{\circ}\right]$ & $\alpha r\left[^{\circ}\right]$ & $\left.\alpha f{ }^{\circ}\right]$ & $\left.\alpha r{ }^{\circ}\right]$ \\
\hline 7,81 & 6,7385 & 6,6553 & 6,6673 & 7,4820 \\
15,62 & SKID & SKID & SKID & SKID \\
23,44 & SKID & SKID & SKID & SKID \\
31,25 & SKID & SKID & SKID & SKID \\
\hline \hline
\end{tabular}

Pada tabel 1 dapat diketahui hasil perhitungan yang menunjukkan bahwa semakin banyak penumpang yang ada di dalam kendaraan maka sudut slip yang terjadi pada ban depan dan belakang kendaraan akan semakin meningkat.

\section{Pengaruh Permukaan Jalan terhadap Sudut Slip Ban}

Pada tabel 2 dapat diketahui hasil perhitungan yang menunjukkan bahwa sudut slip ban akan lebih besar ketika kendaraan melintas pada jalan tanah dibandingkan pada jalan aspal.

Tabel 2 .

Sudut slip rata-rata ban depan $\left(\alpha_{\mathrm{f}}^{\circ}\right)$ serta ban belakang $\left(\alpha_{\mathrm{r}}^{\circ}\right)$ kendaraan dengan 2 penumpang, pada kecepatan $35 \mathrm{Km} / \mathrm{Jam}$, dan tekanan ban sebesar 35 Psi.

\begin{tabular}{lcccc}
\hline \hline$\delta \mathrm{f}\left[^{\circ}\right]$ & $\begin{array}{c}\alpha \mathrm{Jalan}\left[^{\circ}\right] \\
\text { Aspal }\end{array}$ & $\begin{array}{c}\text { Jalan } \\
\text { Tanah }\end{array}$ & $\begin{array}{c}\text { Jalan } \\
\text { Aspal }\end{array}$ & $\begin{array}{c}\text { Jalan } \\
\text { Tanah }\end{array}$ \\
\hline 7,81 & 6,6276 & 6,9087 & 6,2243 & 6,4559 \\
15,62 & SKID & SKID & SKID & SKID \\
23,44 & SKID & SKID & SKID & SKID \\
31,25 & SKID & SKID & SKID & SKID \\
\hline \hline
\end{tabular}

Pada gambar 10 dapat dilihat bahwa sudut slip pada ban depan kendaraaan mengalami peningkatan pada tekanan 25 hingga 30 Psi, namun pada tekanan 35-40 Psi cenderung mengalami penurunan. Apabila dipilih tekanan ban yang dapat memberikan sudut slip terkecil maka dipilih yang 40 Psi. Namun, pada analisa skid dapat diketahui bahwa kecepatan skid kendaraan mengalami penurunan seiring dengan penambahan tekanan ban. Oleh sebab itu tekanan ban yang mampu memberikan perilaku arah belok paling baik dipilih, yaitu sebesar 35 Psi.

D. Pengaruh Sudut Belok dan Kecepatan terhadap Sudut Slip Ban

Pada tabel 3 Dapat dilihat bahwa sudut slip pada ban kendaraan akan mengalami kenaikan sering dengan penambahan sudut belok dan kecepatan. Untuk tabel yang berwarna hijau menunjukkan kondisi kendaraan yang sudah mengalami skid sehingga pada kondisi ini besarnya sudut slip yang terjadi tidak bisa diketahui secara pasti. 


\section{E. Pengaruh Tekanan Ban terhadap Sudut Slip Ban}

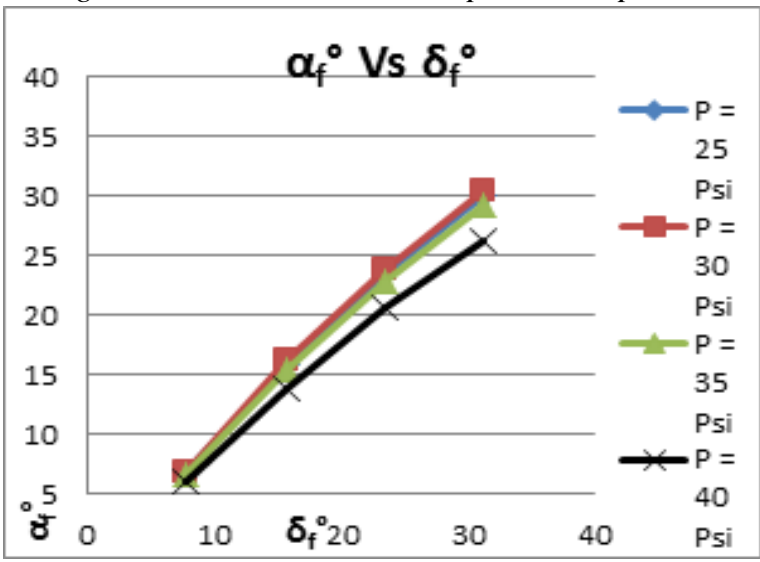

Gambar 10. Grafik nilai $\alpha_{\mathrm{f}}^{\circ}$ Vs $\delta_{\mathrm{f}}^{\circ}$ mobil Toyota Fortuner dengan 2 orang penumpang dengan kecepatan $35 \mathrm{Km} / \mathrm{Jam}$ pada jalan aspal.

Tabel 3.

Sudut slip rata-rata ban depan $\left(\alpha_{\mathrm{f}}^{\circ}\right)$ serta ban belakang $\left(\alpha_{\mathrm{r}}^{\circ}\right)$ kendaraan dengan 2 penumpang, pada jalan aspal, dan tekanan ban sebesar 35 Psi.

\begin{tabular}{|c|c|c|c|c|c|c|}
\hline \multirow{2}{*}{$\delta_{\mathrm{f}}{ }^{\circ}$} & \multicolumn{2}{|c|}{$10 \mathrm{~km} / \mathrm{jam}$} & \multicolumn{2}{|c|}{$15 \mathrm{~km} / \mathrm{jam}$} & \multicolumn{2}{|c|}{$20 \mathrm{~km} / \mathrm{jam}$} \\
\hline & $\alpha_{\mathrm{f}}^{\circ}$ & $\alpha_{r}^{\circ}$ & $\alpha_{f}^{\circ}$ & $\alpha_{\mathrm{r}}^{\circ}$ & $\alpha_{\mathrm{f}}^{\circ}$ & $\alpha_{\mathrm{r}}^{\circ}$ \\
\hline 7,81 & 0 & 0 & 0 & 0 & 0 & 0 \\
\hline 15,62 & 0 & 0 & 0 & 0 & 2,8542 & 2,9887 \\
\hline 23,44 & 0 & 0 & 1,6261 & 1,9315 & 5,9840 & 6,1775 \\
\hline 31,25 & 0 & 0 & 3,3690 & 3,7810 & 8,6735 & 9,1590 \\
\hline \multirow{2}{*}{$\delta_{\mathrm{f}}{ }^{\circ}$} & \multicolumn{2}{|c|}{25 km/jam } & \multicolumn{2}{|c|}{$30 \mathrm{~km} / \mathrm{jam}$} & \multicolumn{2}{|c|}{$35 \mathrm{~km} / \mathrm{jam}$} \\
\hline & $\alpha_{f}^{\circ}$ & $\alpha_{\mathrm{r}}^{\circ}$ & $\alpha_{\mathrm{f}}^{\circ}$ & $\alpha_{\mathrm{r}}^{\circ}$ & $\alpha_{f}^{\circ}$ & $\alpha_{\mathrm{r}}^{\circ}$ \\
\hline 7,81 & 1,36247 & 1,4977 & 3,8655 & 3,7485 & 6,6276 & 6,2243 \\
\hline 15,62 & 6,61740 & 6,5076 & 10,8468 & 10,4609 & SKID & SKID \\
\hline 23,44 & 11,0269 & 11,0929 & SKID & SKID & SKID & SKID \\
\hline 31,25 & 14,8019 & 15,3958 & SKID & SKID & SKID & SKID \\
\hline \multirow{2}{*}{$\delta_{\mathrm{f}}^{\circ}$} & \multicolumn{2}{|c|}{$40 \mathrm{~km} / \mathrm{jam}$} & \multicolumn{2}{|c|}{$45 \mathrm{~km} / \mathrm{jam}$} & \multicolumn{2}{|c|}{$50 \mathrm{~km} / \mathrm{jam}$} \\
\hline & $\alpha_{\mathrm{f}}^{\circ}$ & $\alpha_{\mathrm{r}}^{\circ}$ & $\alpha_{f}^{\circ}$ & $\alpha_{\mathrm{r}}^{\circ}$ & $\alpha_{f}^{\circ}$ & $\alpha_{r}^{\circ}$ \\
\hline 7,81 & 9,6305 & 8,9131 & SKID & SKID & SKID & SKID \\
\hline 15,62 & SKID & SKID & SKID & SKID & SKID & SKID \\
\hline 23,44 & SKID & SKID & SKID & SKID & SKID & SKID \\
\hline 31,25 & SKID & SKID & SKID & SKID & SKID & SKID \\
\hline
\end{tabular}

Berdasarkan hasil perhitungan seperti yang ditunjukkan oleh grafik pada gambar 11, dapat diketahui bahwa mobil Toyota Fortuner memiliki kecepatan skid yang paling tinggi ketika melintasi jalan aspal kering dan paling rendah ketika melintasi jalan tanah basah. Dengan sudut belok $7,81^{\circ}$ kecepatan skid depan kendaraan pada jalan aspal kering mencapai 48,53 $\mathrm{km} / \mathrm{jam}$ sedangkan pada jalan tanah basah hanya mencapai $37,81 \mathrm{~km} / \mathrm{jam}$. Hal ini disebabkan oleh nilai koefisien gesek pada jalan aspal kering yang lebih tinggi daripada permukaan jalan yang lain. Berdsarkan analisa skid dapat dikatakan bahwa mobil Toyota Fortuner mengalami kondisi oversteer karena $\mathrm{V}_{\mathrm{sf}}$ $>\mathrm{V}_{\mathrm{sr}}$.

\section{F. Analisa Guling pada Kendaraan}

Pada gambar 12 dapat diketahui bahwa kecepatan guling kendaraan mengalami penurunan seiring dengan penambahan sudut belok yang diberikan. Hal itu juga terjadi ketika dilakukan penambahan penumpang. Seiring penambahan penumpang menyebabkan titik berat kendaraan bergeser ke atas sehingga menimbulkan momen guling yang besar. Pada sudut belok $7,81^{\circ}$ dengan 1 penumpang, batas kecepatan agar kendaraan tidak terguling total mencapai $71,28 \mathrm{~km} / \mathrm{jam}$ sedangkan dengan 7 orang penumpang hanya sebatas $66,22 \mathrm{~km} / \mathrm{jam}$.

\section{G. Analisa Skid pada Kendaraan}

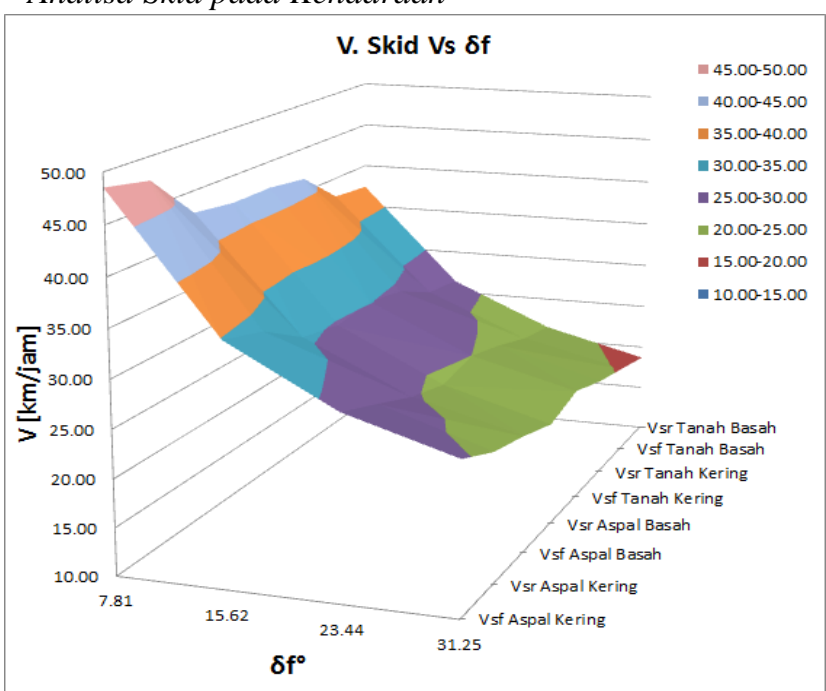

Gambar 11. Grafik batas kecepatan skid Vs $\left(\delta_{\mathrm{f}}{ }^{\circ}\right)$ mobil Toyota Fortuner dengan 2 orang penumpang pada berbagai variasi permukaan jalan.

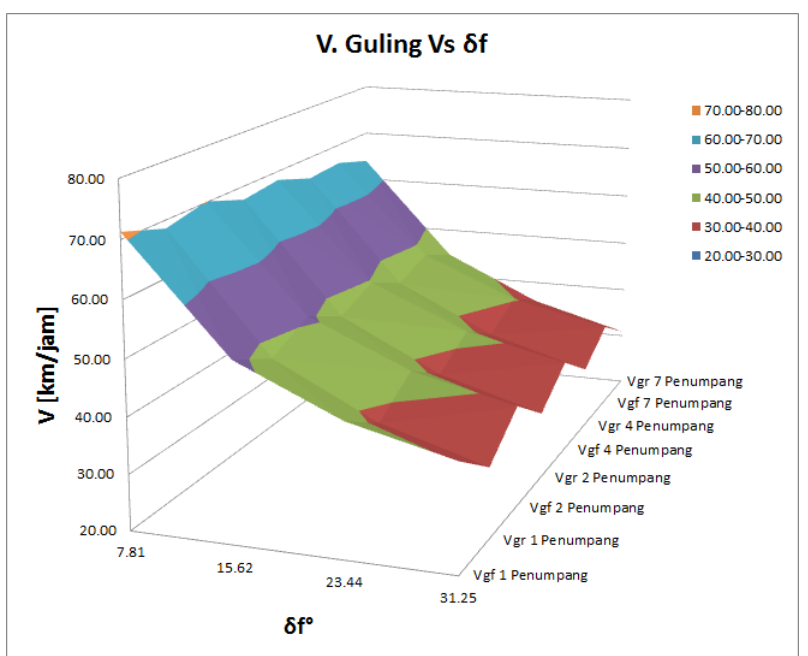

Gambar 12. Grafik batas kecepatan guling dengan sudut belok $\left(\delta_{\mathrm{f}}{ }^{\circ}\right)$ mobil Toyota Fortuner pada berbagai variasi jumlah penumpang.

\section{H. Pengaruh Sudut belok dan Kecepatan terhadap Sudut Guling Kendaraan Belok}

Pada gambar 13 dapat diketahui bahwa semakin besar sudut belok dan kecepatan kendaraan maka besarnya sudut guling yang terjadi menjadi semakin besar.

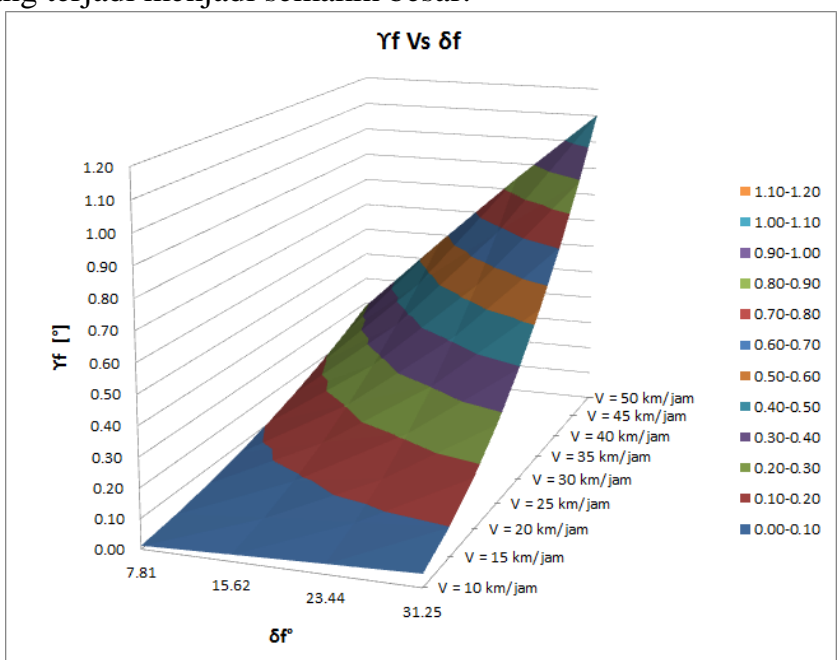

Gambar 13. Grafik besarnya sudut guling depan $\left(\Upsilon_{\mathrm{f}}{ }^{\circ}\right)$ dengan sudut belok $\left(\delta_{\mathrm{f}}{ }^{\circ}\right)$ mobil Toyota Fortuner pada berbagai variasi kecepatan belok dan dinaiki oleh 2 orang penumpang. 


\section{Pengaruh Penggunaan Stabilizer terhadap Sudut Guling dan Kecepatan Guling Kendaraan}

Pada gambar 14 dan tabel 4 dapat diketahui bahwa dengan penambahan stabilizer pada bagian depan maupun belakang menyebabkan besarnya sudut guling pada kendaaran menurun sehingga kecepatan guling kendaraan menjadi semakin meningkat. Sudut guling depan pada sudut belok $15,62^{\circ}$ dan kecepatan $35 \mathrm{~km} / \mathrm{jam}$ mencapai $0,42^{\circ}$ tanpa menggunakan stabilizer dan sebesar $0,28^{\circ}$ ketika menggunakan stabilizer. Dengan semakin kecilnya sudut guling kendaraan saat berbelok maka kecepatan guling kendaraan akan semakin meningkat.

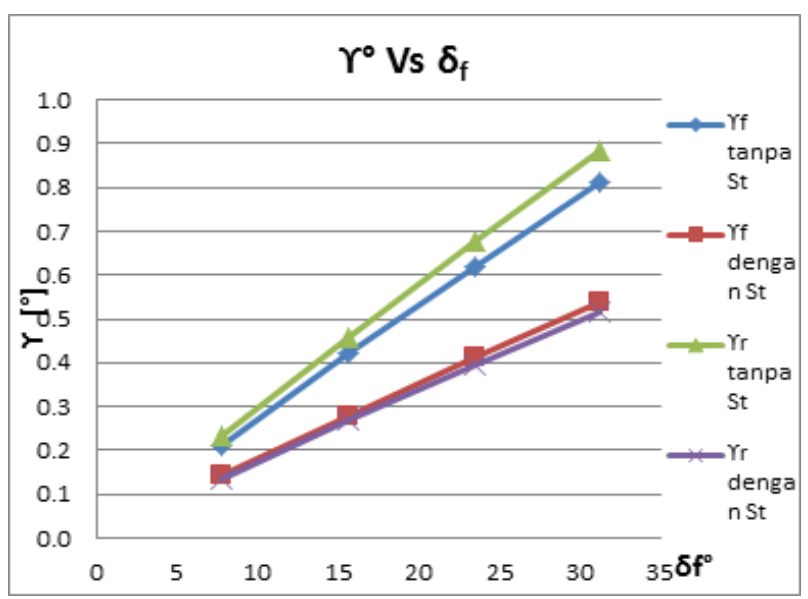

Gambar 14. Grafik besarnya sudut guling depan $\left(\Upsilon_{\mathrm{f}}^{\circ}\right)$ dan belakang kendaraan $\left(\Upsilon_{\mathrm{r}}^{\circ}\right)$ pada kecepatan $35 \mathrm{~km} / \mathrm{jam}$ dengan sudut belok $\left(\delta_{\mathrm{f}}{ }^{\circ}\right)$ dengan dan tanpa menggunakan stabilizer.

Tabel 4.

Kecepatan maksimum guling mobil Toyota Fortuner dengan 2 penumpang, pada jalan aspal, dan tekanan ban sebesar 35 Psi.

\begin{tabular}{|c|c|c|c|c|c|}
\hline $\begin{array}{l}\text { Rsf } \\
{[\mathbf{N} / \mathbf{m}]}\end{array}$ & $\begin{array}{l}\text { Rsr } \\
{[\mathbf{N} / \mathbf{m}]}\end{array}$ & $\begin{array}{l}\text { Pban } \\
\text { [Psi] }\end{array}$ & $\begin{array}{c}\delta \mathbf{f} \\
{\left[{ }^{\circ}\right]}\end{array}$ & $\begin{array}{c}\text { Vgf } \\
{[\mathrm{km} / \mathbf{J a m}]}\end{array}$ & $\begin{array}{c}\text { Vgr } \\
{[\mathrm{km} / \mathrm{Jam}]}\end{array}$ \\
\hline \multirow{4}{*}{$\mathbf{0}$} & \multirow{4}{*}{$\mathbf{0}$} & \multirow{12}{*}{$5^{3}$} & 7,81 & 70,16996 & 67,48480 \\
\hline & & & 15,62 & 50,90678 & 46,83109 \\
\hline & & & 23,44 & 42,81625 & 37,66099 \\
\hline & & & $31 ., 25$ & 38,41586 & 32,23664 \\
\hline \multirow{4}{*}{45340} & \multirow{4}{*}{ 0 } & & 7,81 & 70,17597 & 67,48482 \\
\hline & & & 15,62 & $\begin{array}{r}50,911317 \\
28\end{array}$ & 46,83112 \\
\hline & & & 23,44 & $\begin{array}{r}42,820222 \\
08\end{array}$ & 37,66102 \\
\hline & & & 31,25 & 38,41959 & 32,23668 \\
\hline \multirow{4}{*}{45340} & \multirow{4}{*}{45340} & & $7, .81$ & 70,17595 & 67,48497 \\
\hline & & & 15,62 & 50,91128 & 46,83123 \\
\hline & & & 23,44 & 42,82017 & 37,66110 \\
\hline & & & 31,25 & 38,41954 & 32,23675 \\
\hline
\end{tabular}

J. Hasil Uji Jalan dengan Metode Radius Belok Tetap

Tabel 5.

Perbandingan kecepatan skid kendaraan hasil perhitungan dengan hasil uji jalan.

\begin{tabular}{lrrrc}
\hline \hline $\begin{array}{l}\text { Permukaan } \\
\text { Jalan }\end{array}$ & $\begin{array}{c}\text { Hasil Perhitungan } \\
\text { V.Skid } \\
{[\mathrm{km} / \mathrm{Jam}]}\end{array}$ & \multicolumn{2}{c}{$\begin{array}{c}\text { Hasil Uji Jalan } \\
\text { V. Skid }\end{array}$} & $\begin{array}{l}\left.{ }^{\circ}\right] \\
{[\mathrm{km} / \mathrm{Jam}]}\end{array}$ \\
\hline \multirow{2}{*}{ Aspal kering } & 14,34 & 36,24 & 14,34 & 36 \\
& 14,58 & 35,96 & 14,58 & 36 \\
Tanah kering & 14,72 & 30,98 & 14,72 & 32 \\
& 15,01 & 30,69 & 15,01 & 32 \\
\hline \hline
\end{tabular}

Uji jalan dilakukan dengan radius belok tetap sebesar $10 \mathrm{~m}$. Berdasarkan hasil uji jalan yang telah didapatkan dapat diketahui bahwa nilai $\mathrm{K}_{\mathrm{US}}$ kendaraan pada radius belok $10 \mathrm{~m}$ adalah sebagai berikut.

- $\mathrm{K}_{\mathrm{US}}$ pada jalan aspal dengan stabilizer $=1,8045$

- $\mathrm{K}_{\mathrm{Us}}$ pada jalan aspal tanpa stabilizer $=1,8115$

- $\mathrm{K}_{\mathrm{Us}}$ pada jalan tanahl dengan stabilizer $=2,1511$

- $\mathrm{K}_{\mathrm{US}}$ pada jalan aspal tanpa stabilizer $=2,1641$

Hasil tersebut menunjukkan bahwa kendaraan cenderung mengalami kondisi understeer. Hal ini sesuai dengan hasil perhitungan yang didapatkan untuk radius nyata sebesar $\pm 10 \mathrm{~m}$ yakni mayoritas bernilai positif. Pada tabel 5 dapat diketahui perbandingan besarnya kecepatan skid kendaraan berdasarkan sudut belok yang dihasilkan pada uji jalan.

\section{KESIMPULAN}

Pada penelitian ini dapat diambil beberapa kesimpulan antara lain: mobil Toyota Fortuner akan mengalami kondisi belok paling baik ketika dinaiki oleh 2 orang penumpang dengan memberikan tekanan ban sebesar 35 Psi dan menjalankan kendaraan pada jalan aspal kering karena tidak mudah mengalami skid. Sudut slip yang terjadi pada ban mobil ini akan menjadi lebih besar seiring dengan penambahan jumlah penumpang, sudut belok, serta kecepatan. Berdasarkan analisa skid dapat disimpulkan bahwa kendaraan cenderung mengalami kondisi oversteer karena pada setiap sudut belok dan kondisi permukaan jalan yang diberikan nilai $\mathrm{V}_{\mathrm{sf}}$ selalu lebih besar dari nilai $\mathrm{V}_{\text {sr. }}$. Seperti pada kondisi ketika kendaraan melintas pada jalan aspal kering, dengan sudut belok $7,81^{\circ}$ kecepatan skid depan kendaraan mencapai 48,53 km/jam sedangkan kecepatan skid belakang hanya mencapai 47,62 Km/jam. Berdasarkan analisa guling dapat disimpulkan bahwa mobil Toyota Fortuner mengalami kondisi oversteer karena pada setiap variasi sudut belok serta jumlah penumpag didapatkan nilai $\mathrm{V}_{\text {gf }}$ selalu lebih besar dari nilai $\mathrm{V}_{\mathrm{gr}}$. Ketika mobil dinaiki oleh 2 orang penumpang dengan sudut belok $7,81^{\circ}$, batas kecepatan agar kendaraan tidak terguling depan dan sebesar 70,18 km/jam dan batas kecepatan agar kendaraan tidak terguling belakang sebesar $67,48 \mathrm{~km} / \mathrm{jam}$. Penggunaan stabilizer pada mobil Toyota Fortuner bermanfaat untuk memperkecil sudut guling yang terjadi ketika kendaraan berbelok. Sudut guling depan yang terjadi ketika mobil dikendarai dengan sudut belok $15,62^{\circ}$ pada kecepatan $35 \mathrm{~km} / \mathrm{jam}$ mencapai 1,24 ${ }^{\circ}$ jika tanpa menggunakan stabilizer dan sebesar $0,71^{\circ}$ ketika menggunakan stabilizer. Berdasarkan hasil dari analisa uji jalan dengan radius belok 10 $\mathrm{m}$ dapat disimpulkan bahwa mobil Toyota Fortuner mengalami kondisi understeer karena didapatkan nilai Koefisien Understeer yang bernilai positif yaitu sebesar 1,8045 dan 1,8115 pada jalan aspal serta 2,151 dan 2,1641 pada jalan tanah.

\section{DAFTAR PUSTAKA}

[1] Kantor Kepolisian Republok Indonesia, 2013. Perkembangan Jumlah Kendaraan Bermotor Menurut Jenis Tahun 1987-2013, <URL:http://www.bps.go.id/linkTabelStatis/view/id/1413>; [Accessed 20.11.15].

[2] Dukkipati, R.V., et. all., 2008. "Road Vehicle Dynamic". Warrendale (PA): Society of Automotive Engineers.

[3] Uys, P.E., Els, P.S., Thoresson, M.J., 2006. "Criteria for Handling Measurement". Journal of Terramechanics; 43:43-67.

[4] Cronje, P.H., and Els P.S., 2009. "Improving Off-Road Vehicle Handling Using An Active Anti-Roll Bar”. Journal of Terramechanics: Elsevier.

[5] G. Rill, George., 2006. "Vehicle Dynamics". University of Applied Sciences.

[6] Sutantra, I Nyoman, dan Bambang Sampurno. 2010. Teknologi Otomotif, Edisi Kedua. Surabaya: Guna Widya. 